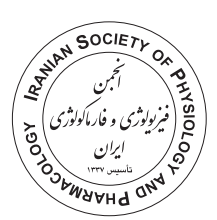

\title{
The effect of swimming exercise on thyroid function, spatial memory and anxiety in normal and propylthiouracil-induced hypothyroidism in Wistar rats
}

Zulkhah Noor $^{1 *}$ (D), Denny Agustiningsih² ${ }^{2}$ Marsetyawan HNE Soesatyo³, Sri Kadarsih Soejono ${ }^{1}$

\author{
1. Physiology Department, Faculty of Medicine and Health Sciences, Muhammadiyah University of Yogyakarta, Yogyakarta, Indonesia \\ 2. Physiology Department, Faculty of Medicine, Public Health and Nursing, Gadjah Mada University, Yogyakarta, Indonesia \\ 3. Histology Department, Faculty of Medicine, Public Health and Nursing, Gadjah Mada University, Yogyakarta, Indonesia
}

\begin{abstract}
Introduction: Swimming exercises improve various nerve growth factors and angiogenesis that encouraged the researchers to investigate the effect of swimming exercises on thyroid function (cyclic adenosine monophosphate [cAMP] and dual oxidase $2\left[\mathrm{DUOX}_{2}\right]$ in free $\mathrm{T}_{4}\left[\mathrm{FT}_{4}\right]$ secretion), spatial memory, behavior and anxiety on normal Wistar pups and those given with propylthiouracil (PTU).

Methods: The subjects of this research were normal Wistar pups and those given $25 \mathrm{ppm}$ PTU from the $1^{\text {st }}$ week until the $12^{\text {th }}$ week of age. Swimming activity was started in 4-weekold pups after acclimatization for 1 week. Swimming exercises were conducted with a load of 1-2\% body weight and 30min duration per day, 5 times a week for 8 weeks. The levels of $\mathrm{FT}_{4}$ serum, cAMP and $\mathrm{DUOX}_{2}$ of the thyroid gland homogenate were measured using enzyme-linked immunosorbent assay. The rats' ability to maintain spatial memory was measured using the Morris water maze and anxiety using the open field maze.

Results: The $\mathrm{FT}_{4}$ levels significantly decreased after the administration of $25 \mathrm{ppm}$ PTU for 3 weeks and it was much more decreased after 12 weeks administration. The administration of 25 ppm PTU for 12 weeks reduced the cAMP levels, increased DUOX ${ }_{2}$ and reduced the spatial memory skills and exploration behavior of rats. Swimming exercise increased and normalized these parameters.

Conclusion: Swimming exercises for 8 weeks improve thyroid function, learning ability and spatial memory of normal and PTU-induced hypothyroid Wistar rats.
\end{abstract}

\section{Introduction}

Adequate levels of thyroid hormones are vital to fetal nervous system development during the growth period. Thyroid function disorders caused by various antithy-

\author{
Keywords: \\ Anxiety \\ cAMP \\ $\mathrm{FT}_{4}$ \\ Propylthiouracil \\ Spatial memory
}

\footnotetext{
* Corresponding author: Zulkhah Noor, zulkhah.noor@umy.ac.id

Received 25 June 2020; Revised from 10 December 2020; Accepted 13 December 2020
}

Citation: Noor Z, Agustiningsih D, HNE Soesatyo M, Soejono SK. The effect of swimming exercise on thyroid function, spatial memory and anxiety in normal and propylthiouracil-induced hypothyroidism in Wistar rats. Physiology and Pharmacology 2021; 25: 231-241. http://dx.doi.org/10.52547/ppj.25.3.231

roid substances consumed for therapy or obtained from food have been observed. The use of antithyroid drugs needs to be approved by a doctor (Taylor and Vaidya, 2012). However, the presence of antithyroid or goitro- 
gens substances found in food and drinks is often not realized, and it disturbs thyroid function nonetheless. Consumption of whole grains containing maximum concentration of glycosyl flavone exerts maximum antithyroid effect and causes a significant increase in thyroid size, accompanied by the inhibition of thyroid peroxidase (TPO) activity (Gaitan et al., 1989). The presence of perchlorate as food contamination interferes with iodine absorption (Pleus and Corey, 2018), reduces thyroid hormone levels and increases thyroid size (Braverman, 2009; Steinmaus et al., 2016). The level of consumption of goitrogen-containing foods in schoolaged children is quite high, for examples processed soy foods (tempeh, tofu, milk and soybean sauce), onions, tomatoes, cassava leaves, cassava, cabbage, broccoli, turnip, mustard greens, radishes, bamboo shoots and legumes (Dewi, 2013; Bajaj et al., 2016). Green tea is a strong goitrogen (Chandra and De, 2010; Sakamoto et al., 2001), which is now widely consumed as a beverage or used as a food flavoring.

Various disorders caused by antithyroid substances, which decreases the free $\mathrm{T}_{4}\left(\mathrm{FT}_{4}\right)$ levels, increases the secretion of thyrotropin-releasing hormone (TRH) and thyroid-stimulating hormone (TSH) (Bajaj et al., 2016). The increase in TSH secretion enables the thyroid follicle cell glands to generate cyclic adenosine monophosphate (cAMP), which is an intracellular messenger that synthesizes the activity of the thyroid hormones (Kronenberg, 2007; Carvalho and Dupuy, 2017). In previous studies, the administration of levothyroxine, which is used in hormone replacement therapy, to improve nerve function by measuring the spatial memory skills of rats with propylthiouracil (PTU)-induced hypothyroidism was tested (Taheri et al., 2018). In some exercises of subjects (experimental animals and humans) with hypothyroidism, an increase in $\mathrm{T}_{3}$ and $\mathrm{T}_{4}$ levels and a decrease in TSH levels were reported (Ciloglu et al., 2005; Shin et al., 2013).

Changes in the levels of cAMP and dual oxidase 2 $\left(\right.$ DUOX $\left._{2}\right)$ as a result of exercise have not been studied much by previous researchers. Increased cAMP demonstrates the sensitivity of thyroid follicular cells to TSH stimulation because cAMP is the second messenger formed by the TSH stimulation. The DUOX ${ }_{2}$ molecule is an enzyme that provides $\mathrm{H}_{2} \mathrm{O}_{2}$ during organification. Changes in the $\mathrm{DUOX}_{2}$ levels due to exercise indicate that exercise's oxidative stress can affect $\mathrm{H}_{2} \mathrm{O}_{2}$ levels.
Therefore, this research is necessary to determine the effects of physical activity or exercise on the action mechanism of thyroid hormone synthesis. The cAMP levels indicate cellular response to TSH stimulation, whereas the DUOX $_{2}$ levels indicate interference with PTU antithyroid substances in the process of organification by TPO in collaboration with $\mathrm{DUOX}_{2}$ as the producer of $\mathrm{H}_{2} \mathrm{O}_{2}$.

Swimming was chosen as the treatment indicator because it is a beneficial training that causes minimal muscle damage (Veskoukis et al., 2018). The swimming training program was found to significantly ameliorate the depression parameters, stress, cognitive flexibility, selective attention and motor coordination in children with attention deficit hyperactivity disorder (Silva et al., 2020). Forced swimming for $10 \mathrm{~min}$ increased blood $\mathrm{T}_{4}$, $\mathrm{T}_{3}$ and TSH levels, pituitary TSH $\beta$ mRNA expression and TRH PVN in rats that underwent adrenalectomy. However, forced swimming for $10 \mathrm{~min}$ in normal mice did not make a significant difference (Sun et al., 2016). Acute swimming causes anxiety, but after the acclimatization process, swimming for more than 15 days does not cause anxiety anymore. Swimming for 30min increases serotonin levels (Higgins, 2019). A 30-min swimming exercise for 4 weeks increases serotonin expression and suppresses apoptosis to reduce anxiety and memory disorders after old age (Park et al., 2020). In addition, swimming treatment in rats does not require expensive tools. This study aimed to examine the effect of swimming exercises on the cAMP and DUOX2 levels of the homogeneous thyroid gland and on the synthesis of $\mathrm{FT}_{4}$ in rats that had thyroid dysfunction due to PTU administration.

\section{Material and methods}

This study uses experimental and pretest-posttest control group designs. The initial and final data were measured to analyze the changes and differences in the thyroid function of $\mathrm{FT}_{4}$ synthesis and secretion. The cAMP and DUOX $_{2}$ levels of the thyroid gland homogenate, spatial memory skills and anxiety were measured at the end of the research.

\section{Research and subject's maintenance}

This study was approved by the Ethics Committee of Research at Gadjah Mada University with certificate No. KE/FK/1372/EC on 28 December 2018 and 
amendment approval was given on 4 July 2019. The subjects of this study were six Wistar rat mothers and their newborn pups that were obtained from the Faculty of Pharmacy at Gadjah Mada University. The animals were kept in $40 \times 30 \times 15 \mathrm{~cm}$ cages during breastfeeding and $25 \times 17 \times 12 \mathrm{~cm}$ cages after being grouped according to the treatment at the UGM PAU Laboratory. The food compositions were water: maximum of $12 \%$, crude protein: minimum of $18 \%$, crude fat: $3-7 \%$, crude fiber: $6 \%$, calcium: $0.9 \%-1.1 \%$, phosphor: minimum of $0.5 \%$ and distilled water for drinking. The food and drink were given ad libitum. The 12:12 h light/dark cycle was used and the room was equipped with blowers and an air conditioner with $21-24^{\circ} \mathrm{C}$ air temperature. After 5 weeks of treatment, the rats were transferred to the UGM Physiology Laboratory for spatial memory, behavior and anxiety measurements. The Physiology Laboratory used blowers but did not use an air conditioner, so the room temperature ranged from 25 to $28^{\circ} \mathrm{C}$.

\section{The administration of PTU}

After the six Wistar rat mothers and their pups underwent the adaptation period, three breastfeeding mothers were given 25 ppm of antithyroid PTU (Behzadi et al., 2018; Goldey et al., 1995) mixed in the drinking water, which started on the $7^{\text {th }}$ day after giving birth (Gilbert, 2011) and the rest was remained normal without any PTU administration. The number of pups per mother varied from 7 to 11 . The Wistar pups and their mothers were not separated because the pups continued to suckle for 28 days. After weaning, the pups were continuously given antithyroid PTU mixed in their drinking water until the end of the study (Shin et al., 2013). Rats were grouped according to the treatment, gender and weight, with each group having 10 rats ( 7 male and 3 female). The treatment groups in this research were the non-PTU (normal) group, normal+ swimming group, PTU group and PTU+ swimming group.

\section{Swimming exercises}

The pups were acclimatized to swimming at 3-5 weeks of age. The swimming protocol in rat pups followed a study on rat pups in the growth period (Simkin et al., 1989 ) with modifications. A rectangle swimming pool $(50 \times 100 \mathrm{~cm})$ was used with a water depth of $20-30 \mathrm{~cm}$ adjusted for large rats. Surface blocks were used to separate two rats that were simultaneously swimming. The water temperature was between $31-34^{\circ} \mathrm{C}$, slightly lower than rats' core temperature to prevent rats become hyperthermic or hypothermic and maintaining the normal hemodynamic system (Kregel, et al., 2006; Stone, et al., 2015). Swimming exercises were performed five times per week for 8 weeks (Nermin et al., 2018). Swimming training in rats started at the age of 5 weeks. The time for swimming was between 9:00 and 15:00 and the swimming duration was 30min for each training (Stone et al., 2015). Bodyweight of $1-2 \%$ was used during the load administration when swimming, which started in week 5. The load was in the form of metal tied to the tail with a rope.

Measurement of $\mathrm{FT}_{4}$ serum hormones, cAMP and $D U O X_{2}$ levels of the thyroid gland homogenates

The serum collection for the measurement of FT4 levels was performed at the beginning (4-week-old pups) and the end of the research. At the end of the research, rats were anesthetized with ketamine and their blood was drawn to collect serum by centrifuging at a speed of $5000 \mathrm{rpm}$ for $10 \mathrm{~min}$. Serum $\mathrm{FT}_{4}$ levels were measured using enzyme-linked immunosorbent assay (ELISA) (Biotech Laboratories, Shanghai, China). Then, the thyroid gland was removed and separated from the surrounding tissue, washed with phosphate-buffered saline (PBS) and stored at $-20^{\circ} \mathrm{C}$ to be measured immediately the next day. The selection of temperature was based on general ELISA sample preparation protocol for less than 1-month stored samples (Xia, 2018). When measuring the DUOX ${ }_{2}$ and cAMP levels, the thyroid gland was defrosted at room temperature, then a $10 \%(\mathrm{~m} / \mathrm{v})$ homogenate was made in sterile PBS and DUOX ${ }_{2}$, and cAMP levels were measured using ELISA, following the procedure from the Bioassay Technology Laboratory.

\section{Spatial memory}

The ability to maintain spatial memory were measured using the Morris water maze (MWM) to evaluate memory associated with space, fields, shape recognition, distance, area and knowledge on direction and position. Each rat was given two trials per day for 8 consecutive days. In each experiment, the rats swam for 60 s to find the hidden platforms. The time when the rats found the platform was recorded (escape latency). If it did not work in 60 s, the rat was given a 60 -s latency score. When successful, rats were allowed a 30 -s rest 
on the platform. Memory retention tests (probe trials) were conducted to examine animals' abilities to maintain spatial memory against the platform location. Rats underwent memory persistence tests twice the following day ( $24 \mathrm{~h}$ after the trial completion). Conducting probe test without the platform in the pool aimed to measure rats' memory of the previous platform location. This was done by measuring the percentage of time spent and swimming distance in the previous target quadrant and the number of crossings above the previous platform location. This assessment provided a second estimation of the rats' memory strength and accuracy of the previous platform location (Terry, 2009). Videos were recorded to measure the time and distance of the rats swimming.

\section{Anxiety}

Rats' anxiety and behavior was measured using the open field maze (OFM). The OFM can be used to measure behavior, locomotor and anxiety (Lecorps et al., 2016; Seibenhener and Wooten, 2015). At the end of the research, the measurement was performed once. Rats were placed in an open box $(120 \times 120 \times 50 \mathrm{~cm})$ for $10 \mathrm{~min}$. The rats' behaviors were recorded using a camera. The parameters measured in the OFM were the number of crossing, standing (rearing), and the number of rat defecations. Rats that were crossing exhibited courage, whereas rats that were standing (rearing) exhibited an exploratory behavior. Also, the increasing number of rat defecations exhibited a high level of anxiety (Seibenhener and Wooten, 2015).

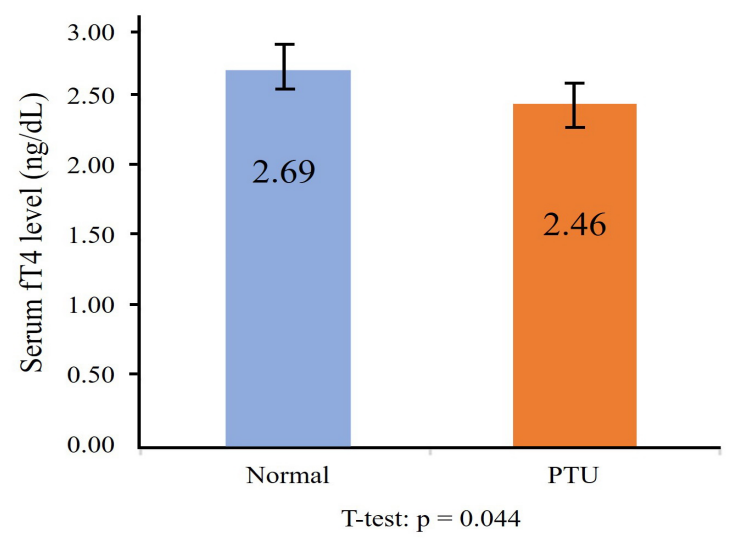

FIGURE 1. The differences in serum free $\mathrm{T}_{4}\left(\mathrm{FT}_{4}\right)$ levels of normal rats and the rats that received $25 \mathrm{ppm}$ propylthiouracil (PTU) for three weeks.

\section{Statistical analysis}

Data analysis performed in this study was paired t-test, independent t-test, Pearson correlation, and oneway ANOVA continued by LSD post hoc.

\section{Results}

The serum $\mathrm{FT}_{4}$ levels measurement at the beginning of the study, before the pups started swimming, is presented in Figure 1. The $\mathrm{FT}_{4}$ levels in 25 ppm PTU administration for 3 weeks group experienced a statistically significant decrease $(\mathrm{P}=0.044)$, even though these levels were still within the normal limits. The differences in the $\mathrm{FT}_{4}$ levels of rat serum based on the treatment group after 8 weeks of swimming exercise are presented in Figure 1.

The schematic shows the differences in the $\mathrm{FT}_{4}$ levels of rat serum based on the treatment group after 8 weeks of swimming exercise (Fig. 2). There was no significant difference in $\mathrm{FT}_{4}$ serum levels between the normal and normal+ swimming groups $(\mathrm{P}=0.460)$, and the $\mathrm{FT}_{4}$ levels in the PTU group were significantly lower than those in the normal group $(\mathrm{P}=0.007)$ and $\mathrm{PTU}+$ swimming group $(\mathrm{P}=0.0141)$. Figure 3 presents the average cAMP level of the thyroid gland homogenate. The highest cAMP level after treatment was found in the normal + swimming group $(\mathrm{P}=0.015)$. The cAMP levels in the PTU+ swimming group were higher than the PTU group, but not significant $(\mathrm{P}=0.232)$.

A schematic of the thyroid gland homogenates cAMP levels positively and strongly correlated with serum $\mathrm{FT}_{4}$ $(\mathrm{r}=0.936, \mathrm{P}=0.013$, Fig. 4). This shows that an increase

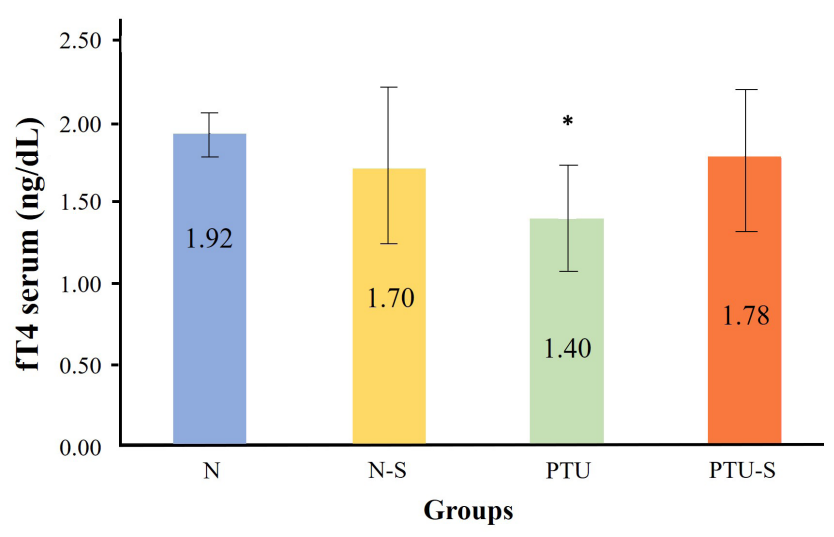

FIGURE 2. A schematic showing the differences in the free $\mathrm{T}_{4}\left(\mathrm{FT}_{4}\right)$ levels of rat serum based on the treatment group after 8 weeks of swimming exercise. $\mathrm{N}=$ normal; $\mathrm{N}-\mathrm{S}=$ normal swimming; $\mathrm{P}=$ propylthiouracil; $\mathrm{P}-\mathrm{S}=$ propylthiouracil swimming. 


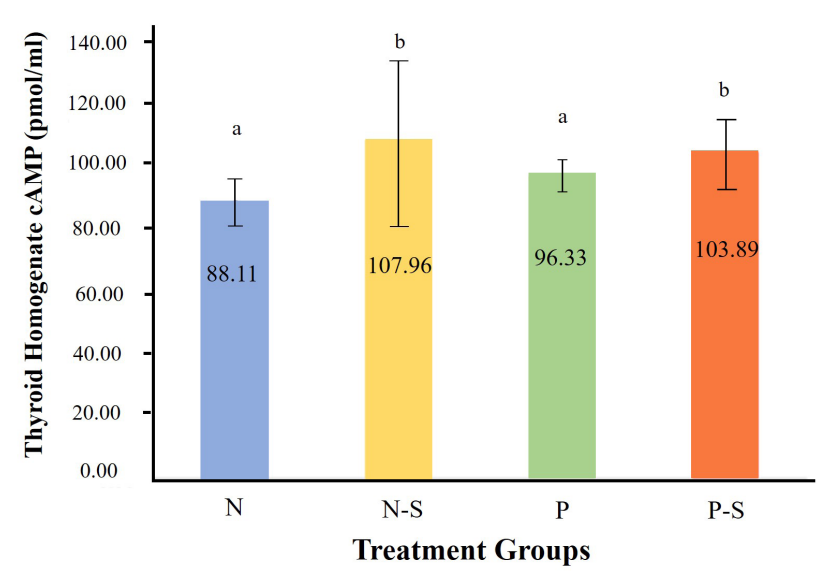

FIGURE 3. The Differences in cAMP levels of rat thyroid gland homogenate between treatment groups. $\mathrm{N}=$ normal; $\mathrm{N}-\mathrm{S}=$ normal swimming; $\mathrm{P}=$ propylthiouracil; $\mathrm{P}-\mathrm{S}=$ propylthiouracil swimming. Different letter notation ( $\mathrm{a}$ and $\mathrm{b}$ ) above the bar is considered significant after an LSD posthoc test $(P<0.05)$.

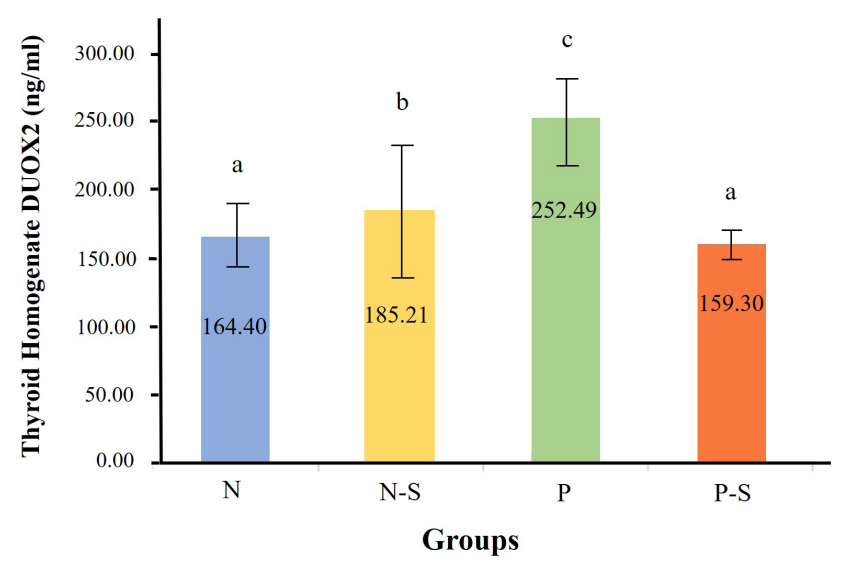

FIGURE 5. The Differences in dual oxidase $2\left(\right.$ DUOX $\left._{2}\right)$ levels in rat thyroid gland homogenate between treatment groups. $\mathrm{N}=$ normal; $\mathrm{N}-\mathrm{S}=$ normal swimming; $\mathrm{P}=$ propylthiouracil; $\mathrm{P}-\mathrm{S}=$ propylthiouracil swimming. Different letter ( $a, b$ and c) notation above the bar is considered significant after a Mann-Whitney test $(P<0.05)$.

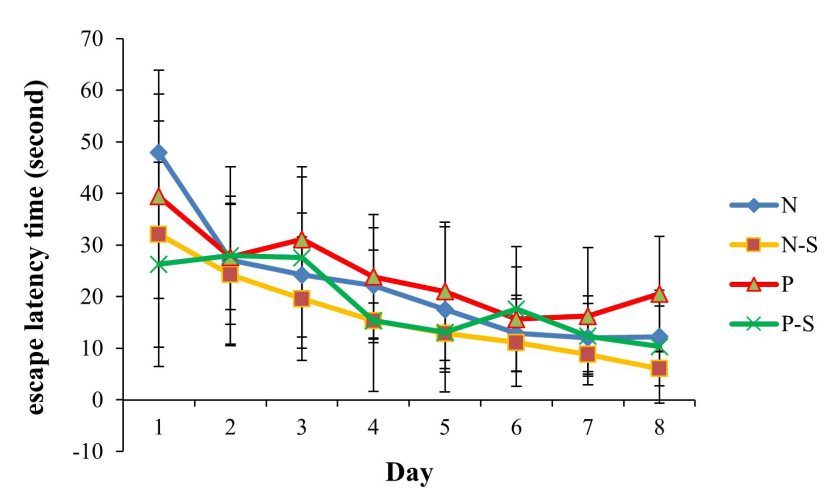

FIGURE 7. The average latency time of the Morris water maze. $\mathrm{N}=$ normal; $\mathrm{N}-\mathrm{S}=$ normal swimming; $\mathrm{P}=$ propylthiouracil; $\mathrm{P}-\mathrm{S}=$ propylthiouracil swimming. The error bar represents standard error.

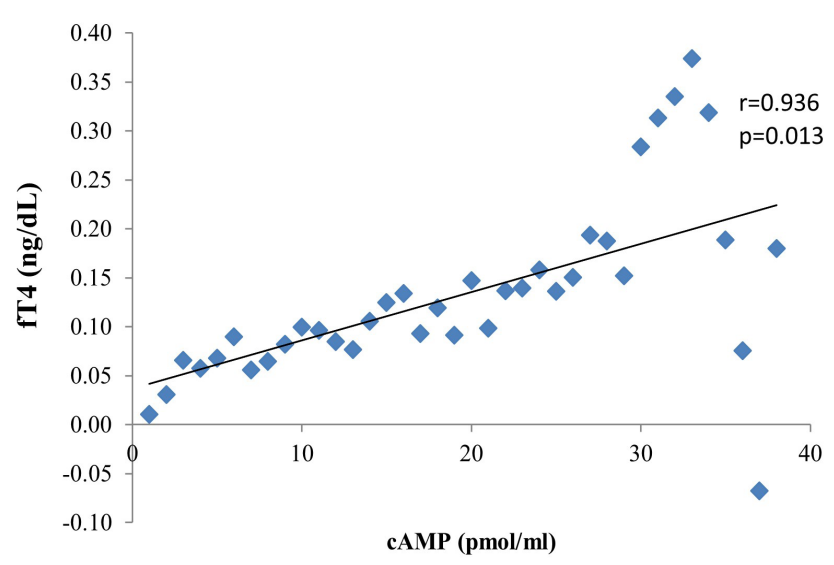

FIGURE 4. The Correlation graft between the cAMP levels of the thyroid gland homogenates with serum $\mathrm{FT}_{4}$.

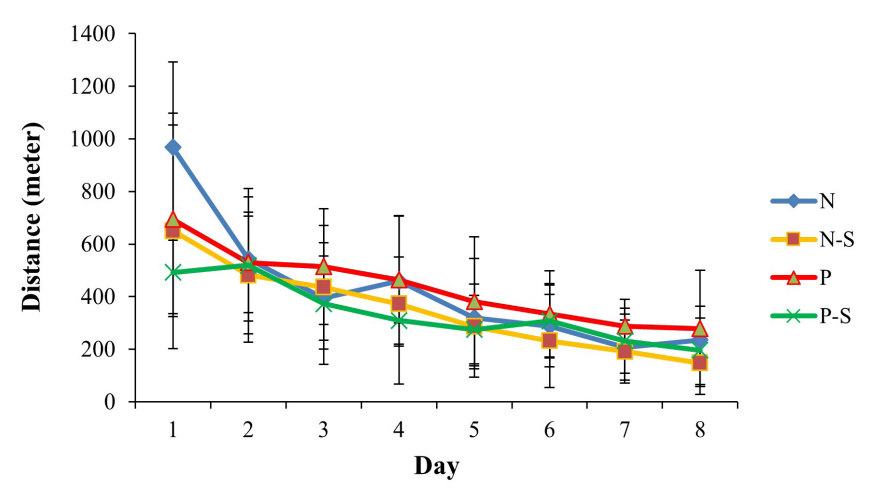

FIGURE 6. The average path length of the Morris water maze. N= normal; $\mathrm{N}-\mathrm{S}=$ normal swimming; $\mathrm{P}=$ propylthiouracil; $\mathrm{P}-\mathrm{S}=$ propylthiouracil swimming. The error bar represents standard error.

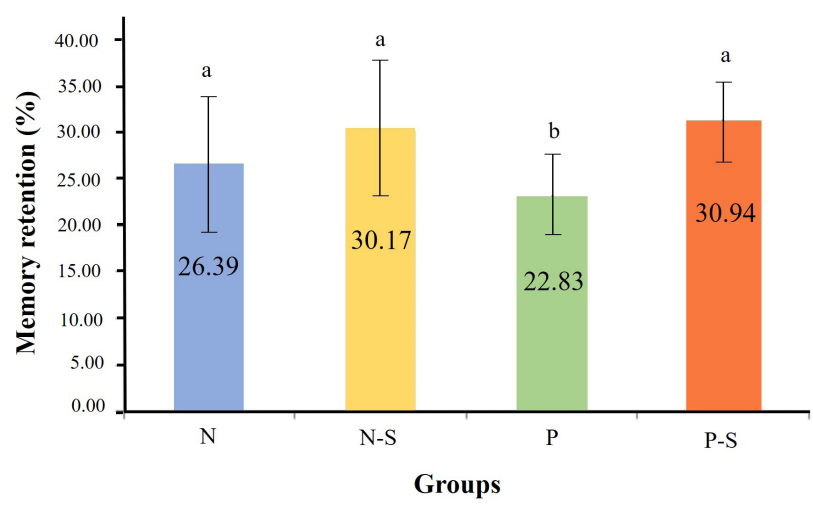

FIGURE8. Differences in spatial memory retention on platform locations in the Morris Water Maze test among treatment groups. $\mathrm{N}=$ normal; $\mathrm{N}-\mathrm{S}=$ normal swimming; $\mathrm{P}=$ propylthiouracil; $\mathrm{P}-\mathrm{S}=$ propylthiouracil swimming. Different letter notation ( $a$ and $b$ ) above the bar is considered significant after an LSD posthoc test $(P<0.05)$. 


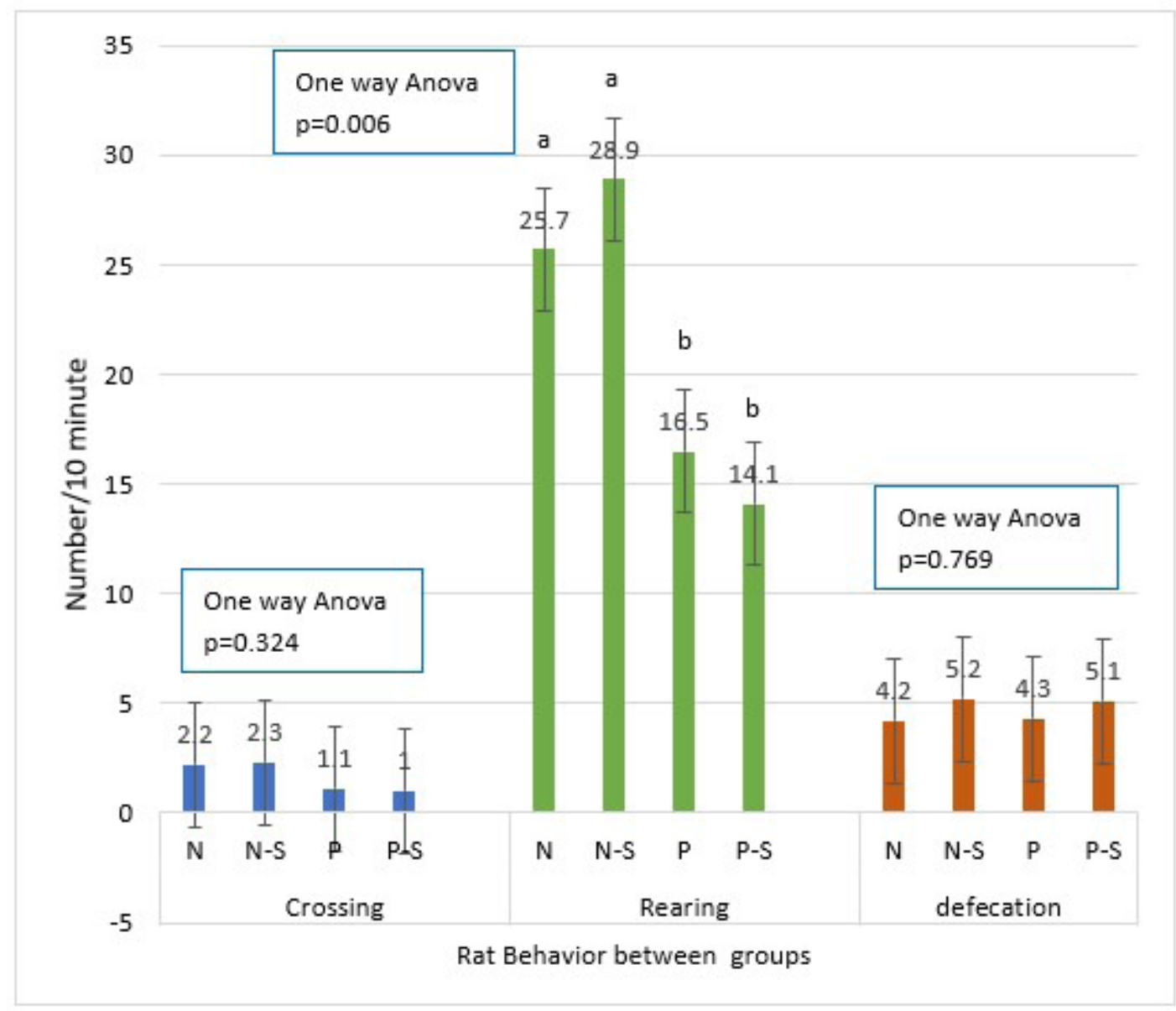

FIGURE 9. The difference between the number of crossing, rearing, and defecation rats in the open field maze test among treatment groups. $\mathrm{N}=$ normal; $\mathrm{N}-\mathrm{S}=$ normal swimming; $\mathrm{P}=$ propylthiouracil; $\mathrm{P}-\mathrm{S}=$ propylthiouracil swimming. Different letter notation $(\mathrm{a}$ and $\mathrm{b})$ above the bar is considered significant after an LSD posthoc test $(P<0.05)$.

in intracellular cAMP accumulation will increase the serum $\mathrm{FT}_{4}$ levels. The highest level of $\mathrm{DUOX}_{2}$ in the thyroid gland homogenate was in the PTU group and the lowest was in the PTU+ swimming group, yet the level of $\mathrm{DUOX}_{2}$ in the PTU+ swimming group was not different from the normal DUOX 2 level (Figure 5). The results of subsequent research are parameters of memory and behavior. Rats' ability to maintain spatial memory was measured using the MWM and the behavior using the OFM.

The graphs of the distances and the latency time of rats in finding the platform in the MWM as shown in Figures 6 and 7. It can be concluded that all groups learned well because, in the last days, all rats were able to find the platform before $60 \mathrm{~s}$. Although not significant, the graph line of the PTU group is at the longest time position. This indicates that the PTU group traveled a long distance $(P=0.058)$ and spent a long latency time $(P=0.181)$ in finding the platform. Meanwhile, the data of the PTU+ swimming group was parallel to the normal group. The normal+ swimming group was the best in learning to find the platform of MWM. This is explained in the memory retention test results in Figure 8.

The measurement of rat behavior using the OFM (Figure 9) shows that there is no difference in terms of the courage to cross, even though it can be seen that the normal group was better than the PTU group from the observed numbers. The normal + swimming group exhibited the best exploration behavior in rearing; however, the difference was not significant compared to the normal group. The exploration behaviors of the PTU and PTU+ swimming groups were significantly lower than those of the normal and normal+ swimming groups. In the number of defecations, no significant differences were observed among the treatment groups.

\section{Discussion}

The $\mathrm{FT}_{4}$ level of the group receiving $25 \mathrm{ppm}$ PTU for 3 weeks experienced a statistically significant decrease, even though the levels were still within the normal lim- 
its. These results are consistent with the results of previous studies in Sprague Dawley rats that the administration of 30 ppm PTU dose decreases $\mathrm{FT}_{4}$ and $\mathrm{FT}_{3}$ serum levels equivalent to the doses of 100 and $300 \mathrm{ppm}$ (Hood, 1999). Prenatal administration of 25 ppm PTU can dramatically reduce the $\mathrm{T}_{4}$ serum levels of Long Evans pups at all ages and induce various developmental disorders (Goldey et al., 1995). In previous research, 25 ppm PTU was administered to eight pregnant dams continuously after birth to postnatal day 60 , which induced congenital hypothyroidism in rats, with the $\mathrm{FT}_{4}$ level of the half from normal (Behzadi et al., 2018). The administration of PTU $0.025 \%$ to Wistar rats mixed in drinking water, from the 1 st day of pregnancy to the 21 st day postnatal, insignificantly reduced the $\mathrm{FT}_{4}$ and $\mathrm{FT}_{3}$ levels in pups on day 60 . However, the administration of PTU $0.025 \%$ postnatal starting from the 1 st day of lactation to the age of 21 days significantly decreased the $\mathrm{FT}_{4}$ and $\mathrm{FT}_{3}$ levels on day 60 (Hamouli-Said et al., 2007). The dose is 10 times greater than the dose used in this study. Research on Wistar rats administered with lower PTU doses (PTU doses 1.5, 3 and 6 ppm starting on the first day after birth until 12 weeks) was conducted by Taheri et al. (2018). The T4 serum levels decreased significantly in the 6-ppm dose group, yet the decrease was not significant. The $\mathrm{T}_{4}$ serum level decrease in response to the administration of 6 ppm PTU was lower in male rats than female rats.

PTU is one of the antithyroid substances that inhibit TPO activity. Aside from PTU, TPO activity is also inhibited by competitive substances from the carbamazepine group, namely thiouracil, methimazole and carbimazole (Bajaj et al., 2016; Kronenberg, 2007). TPO cannot oxidize its substrate without being oxidized by $\mathrm{H}_{2} \mathrm{O}_{2}$ molecules first. Nowadays, it is known that the enzyme that produces $\mathrm{H}_{2} \mathrm{O}_{2}$ and is associated with oogenesis hormone is the NADPH oxidase, which depends on calcium production and is related to $\mathrm{DUOX}_{2}$.

Swimming activity in rats that received PTU $25 \mathrm{ppm}$ until the end of the study (12 weeks) can maintain high levels of $\mathrm{FT}_{4}$ equivalent to normal rats. This is proven by the measurements of cAMP level in thyroid gland homogenates. The highest cAMP levels after treatment were seen in the normal-swimming group and the next sequence was the PTU-swimming group. The increase in cAMP level indicates a good response of the thyroid gland cells to TSH stimulation. The cAMP is a second messenger that forms intracellular thyroid follicular cells after stimulated by TSH. It relaxes various intracellular responses in the synthesis of thyroid hormones. The function of thyroid cells stimulated by TSH is an increase in I- in the follicular lumen mediated by phospholipase C (PL-C), a gradual increase in NIS expression through the cAMP mechanism and an increase in I-efflux from thyroid cells into colloids mediated by pendrin molecules (Pesce et al., 2012); and increased thyroid bloodstream through the mechanism of nitric oxide synthesis; increased thyroid blood flow through the mechanism of nitric oxide synthesis; the formation of hydrogen peroxide in the synthesis of thyroid hormones is mediated by PL-C; the formation of thyroglobulin and TPO is mediated by cAMP; pinocytosis of thyroglobulin, the release of thyroglobulin into the plasma is mediated by cAMP. Mitogenesis of thyroid cells chained by cAMP. While the mechanism of NADPH formation via the pentose-phosphate pathway is not yet clearly known (Kronenberg, 2007; Carvalho and Dupuy, 2017;).

The highest level of DUOX ${ }_{2}$ was observed in the PTU group. Meanwhile, the lowest DUOX $_{2}$ level was observed in the PTU+ swimming group and this level was not different from the normal $\mathrm{DUOX}_{2}$ level. PTU-induced hypothyroidism in rats will experience organification inhibition by TPO (Furman, 2016; Taylor and Vaidya, 2012). The inhibition of TPO activity activates various components, one of which is $\mathrm{DUOX}_{2}$, which plays a role in the synthesis of $\mathrm{H}_{2} \mathrm{O}_{2}$. DUOX and TPO are in very close locations and work together to maintain optimal levels of $\mathrm{H}_{2} \mathrm{O}_{2}$. Also, the regulation of the relationship between DUOX and TPO is observed in the Gq-phospholipase $\mathrm{C}-\mathrm{Ca}^{2+} /$ protein kinase $\mathrm{C}$ pathway and down-regulated through the Gs-cAMP/protein kinase A pathway (Song et al., 2010)

The DUOX 2 levels in the PTU+ swimming group were not different from the normal group. This phenomenon happens because swimming and other exercises induce oxidative stress and an increase in the reactive oxygen species family (anion superoxide, hydroxyl radical, hydrogen peroxide and hypochlorous acid), which can compensate for the effects of PTU, inhibit TPO activity and decreasing $\mathrm{H}_{2} \mathrm{O}_{2}$. There is evidence that antioxidant supplementation combined with antithyroid methimazole can be useful in reducing oxidative stress (Duntas, 2005).

The role of DUOX in the thyroid gland is to produce 
hydrogen peroxide, which is then used in iodide oxidation mediated by thyroid peroxidase to form a reactive compound (De Deken et al., 2014). DUOX protein forms $\mathrm{H}_{2} \mathrm{O}_{2}$, which is needed for thyroid peroxidase/ TPO activity. TPO plays a role in the synthesis of thyroid hormones. The catalytic activity by $\mathrm{DUOX}_{2}$ is observed in the reaction of $\mathrm{NAD}(\mathrm{P}) \mathrm{H}+\mathrm{O}_{2}=\mathrm{NAD}(\mathrm{P})+$ $+\mathrm{H}_{2} \mathrm{O}_{2}$. The activity of the peroxidase enzyme is inhibited by amino benzohydrazide because of its similarity. While, the activity of NADPH oxidase depends on $\mathrm{Ca}$ ions (Ameziane-El-Hassani et al., 2005). The DUOX $_{2}$ gene mutation was found to be associated with cases of congenital hypothyroidism caused by defects in iodine organification. It is suspected that the presence of DUOX $_{1}$ in thyroid cells can compensate for the presence of DUOX ${ }_{2}$ defects, although not completely (Carvalho and Dupuy, 2017).

The rats were able to learn about space, as shown by the graphs of their path length and latency time to find the platform in the MWM. Our study showed that the normal + swimming group was the best in learning to find the platform in the MWM test. A mild decrease in the ability of the rat to study and remember space is thought to be due to a mild decrease in $\mathrm{FT}_{4}$ levels. In the learning process, normal nerve structure and adequate energy metabolism are needed for outstanding nerve performance. During this time, it was not realized that a mild decrease in thyroxine levels had the same effect as the decrease in nerve performance. Various thyroid function disorders have a direct impact on the working mechanism of the nerves (Ahmed, 2015; Lazarus, 2012). Our research provided evidence that swimming exercises improved thyroid gland function by maintaining the $\mathrm{FT}_{4}$ levels within normal limits. Besides, the far-reaching effects of normal $\mathrm{FT}_{4}$ levels and the direct exercise on the nervous system improve learning and memorization skills. The effect of swimming exercises on nerve function in spatial memory is in line with the therapeutic effect of levothyroxine on rats with PTU-induced hypothyroidism (Taheri et al., 2018).

It has been shown that voluntary and forced exercise in rats induces angiogenesis in the brain (Bloor, 2005; Al-Jarrah et al., 2010)), adipose tissue (Lee, 2018) and heart (Hajje et al., 2014), and increases blood flow and density of the hippocampal blood vessels (Nishijima and Soya, 2006). Even 3 days of training initiated angiogenesis by up-regulating vascular endothelial growth factor
(VEGF) of the heart muscle (Wu et al., 2009). Exercise stimulates the increase in VEGF and BDNF in nerve cell proliferation (Ahmed, 2015). Smooth bloodstream and neural plasticity play a significant role in the integrity of the central nervous system function, brain plasticity and cognitive improvement in kittens (Shafiee et al., 2016) and rats (Kerr et al., 1999).

The rat behavior measured by the OFM exhibited no difference in the courage to cross among all treatment groups, even though it can be seen that the normal groups were better than the PTU group from the presented numbers. The exploration behavior exhibited by standing rats (rearing) was the best in the normal+ swimming group yet the difference was not significant compared with the normal group. The exploration behaviors of PTU and PTU+ swimming groups were significantly lower than those of the normal and normal+ swimming groups. Rearing behavior indicates exploratory behavior. Rearing behavior indicates curiosity about environmental conditions. In mice that practiced swimming, this behavior showed more curiosity about the new environment. The number of rat defecations during the OFM test exhibited no difference among the treatment groups. This indicates that the stress levels of rats in all groups are equivalent.

A mild decrease in the $\mathrm{FT}_{4}$ levels has less impact on stress levels and the courage of rats to take risks by crossing open spaces or in the middle of open spaces. However, the impact is more visible in the exploration behaviors of rats, which indicates learning behavior to know the surrounding conditions. This research shows that swimming exercises tend to improve the behaviors of rats. This is consistent with the evidence that swimming exercises significantly stimulates the expression of several growth factors (BDNF, GDNF, NGF, NT-3, $\mathrm{FGF}_{2}$, VEGF, and IGF-1) and peptides (VGF and NPY), increases anti-apoptotic Bcl-xL expression and normalizes the down-regulation that occurs in chronic mild stress-induced rats (Jiang et al., 2014).

\section{Conclusion}

Swimming exercises for 8 weeks can restore decreased thyroid function caused by PTU and improve thyroid function, learning ability and spatial memory of normal Wistar rats and rats with PTU-induced hypothyroidism. We suggest conducting further research on the effects of swimming training on the thyroid function of subjects 
who consume goitrogens with strong effects, such as green tea and raw vegetables. Also, it is necessary to research the effects of swimming on hypothyroid subjects or subjects undergoing thyroid dysfunction therapy.

\section{Acknowledgment}

The authors express their gratitude to the Ministry of Research, Technology, Higher Education, and UMY for funding this research. Also, the authors thank the late Prof. Dr. Ginus Partadiredja, M.Sc, Ph.D., who gave many suggestions in the research and writing of this manuscript.

\section{Conflict of interest}

The authors declare there is no conflict of interest.

\section{References}

Ahmed RG. Hypothyroidism and brain developmental players. Thyroid Res 2015; 8: 1-2. https://doi.org/10.1186/ s13044-015-0013-7

Al-Jarrah M, Jamous M, Al Zailaey K, Bweir SO. Endurance exercise training promotes angiogenesis in the brain of chronic/progressive mouse model of Parkinson's Disease. NeuroRehabilitation 2010; 26: 369-73. https://doi. org/10.3233/NRE-2010-0574

Ameziane-El-Hassani R, Morand S, Boucher JL, Frapart YM, Apostolou D, Agnandji D, et al. Dual oxidase-2 has an intrinsic $\mathrm{Ca} 2+-$ dependent $\mathrm{H} 2 \mathrm{O} 2$-generating activity. J Biol Chem 2005; 280: 30046-54. https://doi.org/10.1074/jbc. M500516200

Bajaj JK, Salwan P, Salwan S. Various possible toxicants involved in thyroid dysfunction: a review. J Clin Diagn Res 2016; 10: FE01-FE03. https://doi.org/10.7860/ JCDR/2016/15195.7092

Behzadi G, Afarinesh MR, Haghpanah T. Alteration of the nucleus basalis of Meynert afferents to vibrissae-related sensory cortex in de-whiskered adolescent congenital hypothyroid rats. Biochem Biophys Res Commun 2018; 503: 2466-70. https://doi.org/10.1016/j.bbrc.2018.07.001

Bloor CM. Angiogenesis during exercise and training. Angiogenesis 2005; 8: 263-71. https://doi.org/10.1007/s10456005-9013-X

Braverman LE. Environmental perchlorate and the thyroid. In Preedy V, Burrow G, Watson R. Comprehensive handbook of iodine nutritional, biochemical, pathological and therapeutic aspects. Elsevier; 2009: p. 283-5. https://doi. org/10.1016/B978-0-12-374135-6.00029-7
Carvalho DP, Dupuy C. Thyroid hormone biosynthesis and release. Mol Cell Endocrinol 2017; 458: 6-15. https://doi. org/10.1016/j.mce.2017.01.038

Chandra AK, De N. Goitrogenic/antithyroidal potential of green tea extract in relation to catechin in rats. Food Chem Toxicol 2010; 48: 2304-11. https://doi.org/10.1016/j. fct.2010.05.064

Ciloglu F, Peker I, Pehlivan A, Karacabey K, lhan N, Saygin $\mathrm{O}$, et al. Exercise intensity and its effects on thyroid hormones. Neuroendocrinol Lett 2005; 26: 830-4.

De Deken X, Corvilain B, Dumont JE, Miot F. Roles of DUOX-Mediated hydrogen peroxide in metabolism, host defense, and signaling. Antioxid Redox Signal 2014; 20: 2776-93. https://doi.org/10.1089/ars.2013.5602

Dewi YLR. Goitrogenic food consumed by schoolchildren in Ngargoyoso sub-district, karanganyar regency, Central Java, Indonesia. J Nat Sci Res 2013; 3: 51-6.

Duntas LH. Oxidants, antioxidants in physical exercise and relation to thyroid function. Horm Metab Res 2005; 37 : 572-6. https://doi.org/10.1055/s-2005-870425

Furman BL. Antithyroid agents. In: Reference module in biomedical sciences. Elsevier, 2016: B9780128012383980000. https://doi.org/10.1016/B 978-0-12-8012383.98050-4

Gaitan E, Lindsay RH, Reichert RD, Ingbar SH, Cooksey RC, Legan J, et al. Antithyroid and Goitrogenic effects of millet: role of C-glycosylflavones. J Clin Endocrinol Metab 1989; 68: 707-14. https://doi.org/10.1210/jcem-68-4-707

Gilbert ME. Impact of low-level thyroid hormone disruption induced by propylthiouracil on brain development and function. Toxicol Sci 2011; 124: 432-45. https://doi. org/10.1093/toxsci/kfr244

Goldey ES, Kehn LS, Rehnberg GL, Crofton KM. Effects of developmental hypothyroidism on auditory and motor function in the rat. Toxicol Appl Pharmacol 1995; 135: 6776. https://doi.org/10.1006/taap.1995.1209

Hajje G, Saliba Y, Itani T, Moubarak M, Aftimos G, Farès N. Hypothyroidism and its rapid correction alter cardiac remodeling. Plos One 2014; 9: e109753. https://doi. org/10.1371/journal.pone.0109753

Hamouli-Said Z, Tahari F, Hamoudi F, Hadj-Bekkouche F. Comparative study of the effects of pre and post natal administration of a thyroid drug on testicular activity in adult rat. Folia Histochem Cytobiol 2007; 45: 51-7.

Higgins JP. Want to get happy? Exercise. 2019. Retrieved from https://www.houstonchronicle.com/lifestyle/renew-houston/fitness/article/Want-to-get-happy-Exercise-sero- 
tonin-13835803.php

Hood A, Liu YP, Gattone 2nd VH, Klaassen CD. Sensitivity of thyroid gland growth to thyroid stimulating hormone (TSH) in rats treated with antithyroid drugs. Toxicol Sci 1999; 49: 263-71. https://doi.org/10.1093/toxsci/49.2.263

Jiang P, Dang RL, Li HD, Zhang LH, Zhu WY, Xue Y, et al. The impacts of swimming exercise on hippocampal expression of neurotrophic factors in rats exposed to chronic unpredictable mild stress. Evid Based Complement Alternat Med 2014; 2014: 1-8. https://doi. org/10.1155/2014/729827

Kerr BJ, Bradbury EJ, Bennett DL, Trivedi PM, Dassan P, French J, et al. Brain-derived neurotrophic factor modulates nociceptive sensory inputs and NMDA-evoked responses in the rat spinal cord. J Neurosci 1999; 19: 5138-48. https:// doi.org/10.1523/JNEUROSCI.19-12-05138.1999

Kregel KC, Allen DL, Booth FW, Fleshner MR, Henriksen EJ, Musch TI, et al. Resource book for the design of animal exercise protocols. Am Physiol Soc 2006; 152.

Kronenberg H. Williams textbook of endocrinology. Elsevier, London. 2007.

Lazarus JH. Thyroid hormones and cognitive function. Expert Rev Endocrinol Metab 2012; 7: 365-7. https://doi.org/10.1586/eem.12.27

Lecorps B, Rödel HG, Féron C. Assessment of anxiety in open field and elevated plus maze using infrared thermography. Physiol Behav 2016; 157: 209-16. https://doi.org/10.1016/j. physbeh.2016.02.014

Lee HJ. Exercise training regulates angiogenic gene expression in white adipose tissue. J Exerc Rehabil 2018; 14: 1623. https://doi.org/10.12965/jer.1836010.005

Nermin M, Mervat H, Metwali M. Effect of chronic regular swimming exercise on thyroid function in ovariectomized rats. Med J Cairo Univ 2018; 86: 3397-3406. https://doi. org/10.21608/mjcu.2018.60312

Nishijima T, Soya H. Evidence of functional hyperemia in the rat hippocampus during mild treadmill running. Neurosci Res 2006; 54: 186-91. https://doi.org/10.1016/j. neures.2005.11.005

Park SS, Park HS, Kim TW, Lee SJ. Effects of swimming exercise on social isolation-induced memory impairment and apoptosis in old rats. J Exerc Rehabil 2020; 16: 234-41. https://doi.org/10.12965/jer.2040366.183

Pesce L, Bizhanova A, Caraballo JC, Westphal W, Butti ML, Comellas A, et al. TSH regulates pendrin membrane abundance and enhances iodide efflux in thyroid cells. Endocrinology 2012; 153: 512-21. https://doi.org/10.1210/en.2011-
1548

Pleus RC, Corey LM. Environmental exposure to perchlorate: a review of toxicology and human health. Toxicol Appl Pharmacol 2018; 358: 102-9. https://doi.org/10.1016/j. taap.2018.09.001

Sakamoto Y, Mikuriya H, Tayama K, Takahashi H, Nagasawa A, Yano N, et al. Goitrogenic effects of green tea extract catechins by dietary administration in rats. Arch Toxicol 2001; 75: 591-6. https://doi.org/10.1007/s00204001-0286-6

Seibenhener ML, Wooten MC. Use of the open field maze to measure locomotor and anxiety-like behavior in mice. J Vis Exp 2015: 6: e52434. https://doi.org/10.3791/52434

Shafiee SM, Vafaei AA, Rashidy-Pour A. Effects of maternal hypothyroidism during pregnancy on learning, memory and hippocampal BDNF in rat pups: beneficial effects of exercise. Neuroscience 2016; 329: 151-61. https://doi. org/10.1016/j.neuroscience.2016.04.048

Shin MS, Ko IG, Kim SE, Kim BK, Kim TS, Lee SH, et al. Treadmill exercise ameliorates symptoms of methimazole-induced hypothyroidism through enhancing neurogenesis and suppressing apoptosis in the hippocampus of rat pups. Int J Dev Neurosci 2013; 31: 214-23. https://doi. org/10.1016/j.ijdevneu.2013.01.003

Silva LA, Doyenart R, Henrique Salvan P, Rodrigues W, Felipe Lopes J, Gomes K, et al. Swimming training improves mental health parameters, cognition and motor coordination in children with attention deficit hyperactivity disorder. Int J Environ Health Res 2020; 30: 584-92. https://doi.org/1 0.1080/09603123.2019.1612041

Simkin A, Leichter I, Swissa A, Samueloff S. The effect of swimming activity on bone architecture in growing rats. $\mathrm{J}$ Biomech 1989; 22: 845-51. https://doi.org/10.1016/00219290(89)90068-7

Song Y, Ruf J, Lothaire P, Dequanter D, Andry G, Willemse E, et al. Association of duoxes with thyroid peroxidase and its regulation in thyrocytes. J Clin Endocrinol Metab 2010; 95: 375-82. https://doi.org/10.1210/jc.2009-1727

Steinmaus C, Pearl M, Kharrazi M, Blount BC, Miller MD, Pearce EN, et al. Thyroid hormones and moderate exposure to perchlorate during pregnancy in women in Southern California. Environ Health Perspect 2016; 124: 861-7. https:// doi.org/10.1289/ehp.1409614

Stone V, Kudo KY, Marcelino TB, August PM, Matté C. Swimming exercise enhances the hippocampal antioxidant status of female Wistar rats. Redox Report 2015; 20: 133-8. https://doi.org/10.1179/1351000214Y.0000000116 
Sun Q, Liu A, Ma Y, Wang A, Guo X, Teng W, et al. Effects of forced swimming stress on thyroid function, pituitary thyroid stimulating hormone and hypothalamus thyrotropin releasing hormone expression in adrenalectomy Wistar rats. Exp Ther Med 2016; 12: 3167-74. https://doi.org/10.3892/ etm.2016.3790

Taheri M, Haghpanah T, Meftahi GH, Esfahlani MA, Gloshan F, Esmailpour K, et al. Mild permanent chronic thyroid hormones insufficiency induces cognitive dysfunction in the adult male and female rats. J Appl Pharm Sci 2018; 8: 1006. https://doi.org/10.7324/JAPS.2018.8716

Taylor PN, Vaidya B. Side effects of anti-thyroid drugs and their impact on the choice of treatment for thyrotoxicosis in pregnancy. Eur Thyroid J 2012; 1: 176-85. https://doi. org/10.1159/000342920

Terry AV. Spatial navigation (Water maze) Tasks. In: Bucca- fusco JJ, Editors. Methods of behavior analysis in neuroscience. CRC Press/Taylor and Francis, Boca Raton (FL), 2009.

Veskoukis AS, Margaritelis NV, Kyparos A, Paschalis V, Nikolaidis MG. Spectrophotometric assays for measuring redox biomarkers in blood and tissues: the NADPH network. J Redox Report 2018; 23: 47-56. https://doi.org/10.1080/13 510002.2017.1392695

Wu G, Rana JS, Wykrzykowska J, Du Z, Ke Q, Kang P, et al. Exercise-induced expression of VEGF and salvation of myocardium in the early stage of myocardial infarction. Am J Physiol Heart Circ Physiol 2009; 296: H389-95. https:// doi.org/10.1152/ajpheart.01393.2007

Xia CJ. ELISA Ptotocol. Retrieved from dx.doi.org/10.17504/ protocols.io.mf $2 \mathrm{c} 3 \mathrm{qe}$ 